Acta Psychotherap. 1955;3(Suppl. 1):402

\title{
The Dual Aspect of Transference
}

\begin{tabular}{|l|l|l|}
\hline M.M. & Max M. & Stern \\
\hline
\end{tabular}

New York

\section{Summary}

Whereas in Freud's conception transference is related foremost to repressed libidinal wishes, the dual aspect based on the application of Selye's S.A.S. to the concept of trauma, stresses its defensive purpose as well. The primary need for overcoming unresolved, early traumata overrules reality-testing and assigns to the therapist as well as to suitable objects the protective role of the parents which, due to the protective effect of libidinal gratification in early traumatic situations (shock), is imagined as such. Since simultaneously the parents were experienced as the instigators of these traumata, the early defensive reactions will likewise be repeated. "Trauma and Symptom Formation”, Int. J. Psycho-Anal. 1953. 